This paper was published in IET Electrical Systems in Transportation, 2011, doi 10.1049/iet-est.2010.0056, and is available at:

http://ieeexplore.ieee.org/stamp/stamp.jsp?tp=\&arnumber=6034628

R. Todd, A.J. Forsyth, " DC-Bus Power Quality for Aircraft Power Systems During Generator Fault Conditions," IET Electrical Systems in Transportation, vol. 1, no. 3, pp. 126-135, 2011, doi: 10.1049/iet-est.2010.0056

(c) 2014 IET. Personal use of this material is permitted. Permission from the IET must be obtained for all other uses, in any current or future media, including reprinting/republishing this material for advertising or promotional purposes, creating new collective works, for resale or redistribution to servers or lists, or reuse of any copyrighted component of this work in other works. 


\title{
DC-Bus Power Quality for Aircraft Power Systems During Generator Fault Conditions
}

\author{
R. Todd, A.J. Forsyth \\ School of Electrical \& Electronic Engineering, The University of Manchester, UK.
}

Abstract - Higher-voltage, $540 \mathrm{~V}$, aircraft DC-bus power quality is examined experimentally and by computer simulation during a short-circuit fault across the phase terminals of a $70 \mathrm{~kW}$, fivephase, permanent magnet fault-tolerant generator. The DC-bus transients caused by the shortcircuiting of the generator phases are seen to exceed the limits in MIL-STD-704F and a control algorithm is proposed for a supercapacitor based energy storage device that mitigates the transients. The controller performance is illustrated by computer simulations for a range of bus switching scenarios.

Index Terms - Fault-tolerant generator, supercapacitor energy storage, DC-bus power quality

\section{Nomenclature}

$C_{\text {bus }} \quad$ DC-bus capacitor

$C_{s c} \quad$ Supercapacitor

$E \quad$ Magnitude of back emf

$I_{b u s} \quad$ DC-bus current

$I_{E S D / s c} \quad$ ESD / supercapacitor current

$I_{\text {gen }} \quad$ Generator total DC current

$I_{\text {gen-AC }} \quad$ Generator phase current

$I_{s c-F} \quad$ Fault mitigation control reference

$I_{s c-L} \quad$ Power balance control reference

$I_{s c-r c} \quad$ Supercapacitor recharge reference

$k_{c} \quad$ Current regulation proportional term

$k_{v} \quad$ Voltage regulation proportional term

$L_{E S D} \quad$ ESD DC/DC converter inductor

$L_{s} \quad$ Stator inductance per phase

$R_{S} \quad$ Stator resistance per phase

$T_{c} \quad$ Current regulation integral term

$T_{e} \quad$ Generator torque

$V_{\text {bus }} \quad$ DC-bus voltage

$V_{E S D / s c} \quad$ ESD / supercapacitor voltage

$\alpha \quad$ Fault angle

$\omega_{c} \quad$ Current regulation bandwidth

$\omega_{e} \quad$ Electrical angular frequency 
$\omega_{v} \quad$ Voltage regulation bandwidth

\section{Introduction}

The increasing use and criticality of electrical systems on-board aircraft is driving the development of new fault-tolerant generator technologies [1-4] and new power distribution systems such as higher-voltage DC networks [5-9]. However, the behaviour of these integrated systems under fault conditions is not well understood, especially the propagation of transients around the system, which, if uncontrolled, may lead to further equipment malfunction or failure. MIL-STD-704F [10] describes allowable DC-bus power quality limits in terms of voltage deviation and current ripple. Exceeding these limits, during load changes, bus switching events or fault conditions, may result in equipment going offline causing further disruption. In this paper a supercapacitor based energy storage device is used to mitigate the DC-bus transients that result from short-circuit faults across the $\mathrm{AC}$ terminals of a five-phase fault-tolerant generator, load changes and voltage steps.

The generator is one of several technologies that are under investigation for embedding in the core of a jet engine, thereby simplifying the current mechanical power off-take arrangements. The generator has a permanent magnet rotor and five stator phases, each of which is electrically, magnetically and thermally isolated from the others [11]. Furthermore each phase has a high impedance which limits the current flowing in a terminal short-circuit to 1p.u., enabling the machine to continue generating through the healthy phases when one or more windings has a short-circuit fault. However, faulting the generator phases is likely to affect adversely the power quality of the DC-bus, possibly exceeding the voltage deviation limits defined in MIL-STD-704F [10], which is the closest applicable standard.

DC systems are of increasing interest for power distribution on-board aircraft due to the lower system weight that arises from smaller cables and the reduced number of power electronic interfaces [12]. Also, the ability to parallel generators that may be operating asynchronously 
provides increased power management flexibility. 270V DC systems [5, 6] are currently operating on some military aircraft, and \pm 270 V DC (540V) systems are now being suggested [8] for a wider range of higher power applications. However, a number of technical challenges is limiting the development of DC networks such as managing the interactions within the system, interrupting fault currents [8], protection [7, 13], and safety issues. This paper proposes techniques to limit the propagation of generator faults within a 540V DC system.

The system under investigation in this paper is first described followed by experimental results showing short-circuit generator faults. The controller for the energy storage device is then presented followed by simulation results.

\section{System Configuration}

The outputs of the five-phase generator are connected to a 540V ( $\pm 270 \mathrm{~V})$ DC-bus, which supplies a combination of resistive and constant power load [14] units, Fig. 1. The system also includes an energy storage device (ESD) comprising a supercapacitor bank and bi-directional DC/DC converter. Supercapacitor energy storage is used as the key characteristics of this technology, high power density and fast charge / discharge rates [15], are complementary to the generators electrical characteristics.

The primary function of the ESD is to meet transient load demands, thereby protecting the generator and aircraft engine from rapid and / or repetitive load changes [16]. A similar aircraft system with an energy storage device is considered by Zhang et al. [9], however, the primary objectives of the energy storage control in [9] are to maintain the main generator online and to share power between the generator and the energy storage device.

To preserve the fault-tolerance of the generator system, shown in Fig. 1, each phase winding is passed through a separate H-bridge AC/DC converter. The PWM controllers on each H-bridge ensure that the generator currents are sinusoidal and also regulate the DC-bus voltage [17]. Load 
sharing between the H-bridge converters is achieved using simple droop controllers. The generator has a rating of $70 \mathrm{~kW}$, a base speed of 1000rpm and a base electrical frequency of $233 \mathrm{~Hz}$, the nominal DC-bus voltage is set at $540 \mathrm{~V}$ and the DC output voltage of the H-bridges is set to droop by $20 \mathrm{~V}$ at full load [18]. The total capacitance on the $540 \mathrm{~V}$ bus is $800 \mu \mathrm{F}$ and the bandwidth of the generator controller is $60 \mathrm{rad} / \mathrm{s}$.

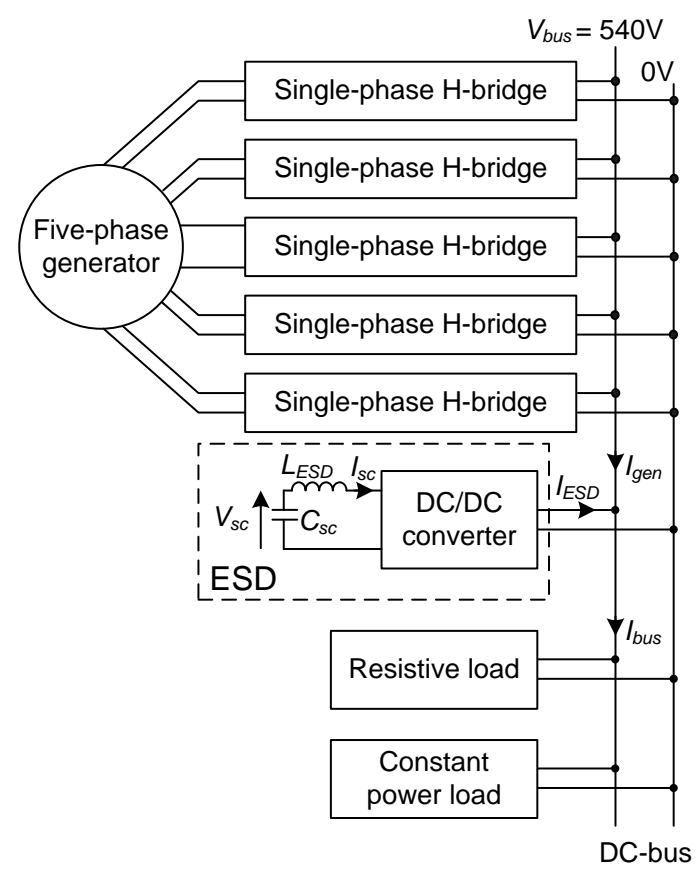

Figure 1. System configuration

In the following sections experimental measurements and simulation results are presented to examine the effect of a short-circuit fault across one of the generator phase terminals. Large voltage deviations in DC-bus voltage are observed, partly at least due to the relatively small value of DC-bus capacitance, and this in turn is due to the requirement to avoid electrolytic capacitor types in aerospace systems. As there are no published standards for the power quality of $540 \mathrm{~V}$ DC aerospace systems, the results are compared with the limits in MIL-STD-704F [10], which relates to 270 V DC supplies. Since the observed deviations in DC-bus voltage during a generator terminal short-circuit fault are well outside the limits set by MIL-STD-704F, the control system for the ESD is modified to provide voltage support for the DC-bus. The system performance 
during multi-phase generator short-circuit winding faults is examined in subsequent sections by means of simulation and is seen to meet the requirements of MIL-STD-704F.

\section{Validated Single-Phase Fault Response}

For convenience the short-circuit fault was applied to the machine winding through the converter by halting the PWM signals so that the top switch in each H-bridge converter leg was permanently closed with the bottom switches open [17]. This condition is representative of the system response to either a machine winding or IGBT fault. In the event of an IGBT short-circuit fault, the system response would be to switch on the corresponding healthy device in the other leg, placing a short-circuit across the phase terminals.

A Simulink-based simulation of the system was developed using lossless averaged-value models of the power electronics. The generator was modelled as five sinusoidal back emfs in series with the corresponding winding inductance and resistance. Friction and windage losses were omitted. In these initial tests the ESD was not connected.

An analytical solution for the short-circuit current in the faulted phase may be derived assuming constant phase inductance and neglecting eddy current effects. The phase equivalent circuit following the short-circuit fault $[3,19]$ is therefore the back emf, $E \cos \left(\omega_{e} t\right)$, in series with the winding resistance and inductance, $R_{s}$ and $L_{s}$. Assuming that the terminal short-circuit is applied at $t=\alpha / \omega_{e}$, the post fault current may be expressed as:

$$
I_{g e n-A C}=\frac{E}{|Z|} \cos \left(\omega_{e} t-\angle Z\right)+I_{e} \exp \left\{\frac{-R_{s}}{L_{s}}\left[t-\frac{\alpha}{\omega_{e}}\right]\right\} \quad \text { for } t \geq \frac{\alpha}{\omega_{e}}
$$

where $I_{e}=-\frac{m V_{b u s}}{|Z|} \cos (\alpha-\delta-\angle Z)$ and $Z=R_{s}+j \omega_{e} L_{s}$

$\omega_{e}$ is the electrical frequency and $\delta$ and $m$ are the angle and the depth of modulation of the Hbridge AC input voltage immediately before the fault is applied. 
Fig. 2 shows the response of the generator to a single-phase short-circuit fault on phase 'c' at approximately $\mathrm{t}=1.03 \mathrm{~s}$. Experimental results [17] are shown in Figs. 2.a. and 2.b. and results from the averaged-value model in Figs. 2.c. and 2.d. The initial operating condition was all five generator phases active at $1001 \mathrm{rpm}, 540 \mathrm{~V}$ nominal DC-bus voltage and a $26.7 \mathrm{~kW}$ resistive load. The per-phase AC and DC currents, $I_{g e n-A C}$ and $I_{g e n-D C}$, respectively, DC-bus voltage, $V_{b u s}$, and torque, $T_{e}$, are shown in the results. $I_{g e n-D C}$ is filtered by a $4.66 \mathrm{~Hz}$ low pass filter to remove the second-harmonic component prior to its use in the generator droop controllers which ensure balanced phases.

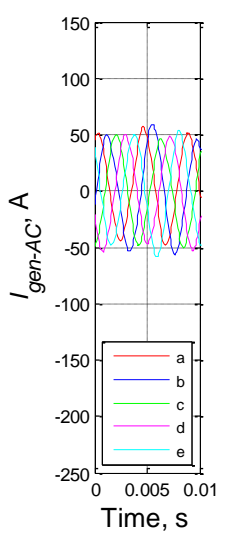

(i)

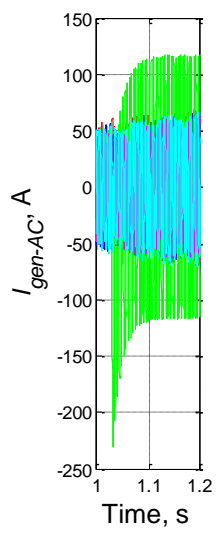

(ii)

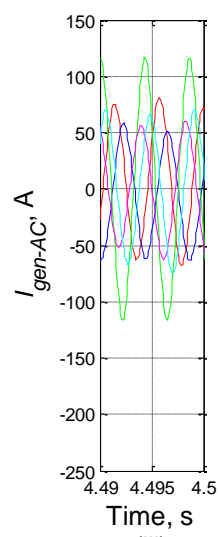

(iii)

a. experimental result [17]

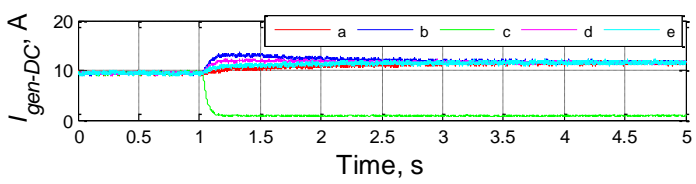

(i)

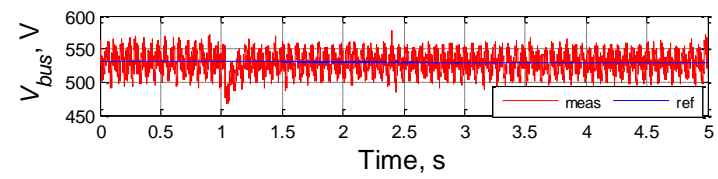

(ii)

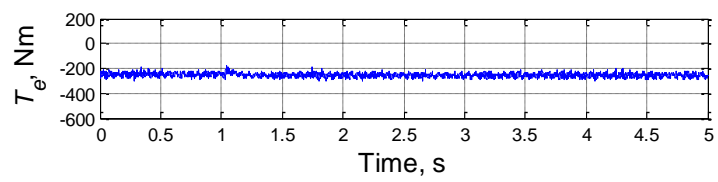

(iii)

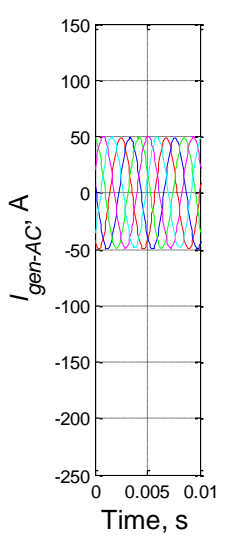

(i)

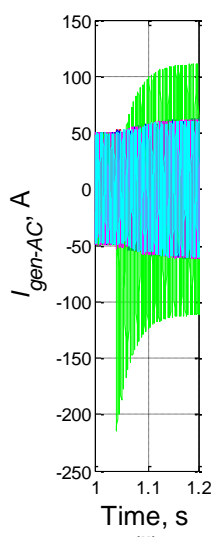

(ii)

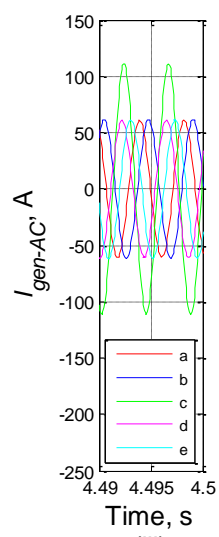

(iii) c. simulation result

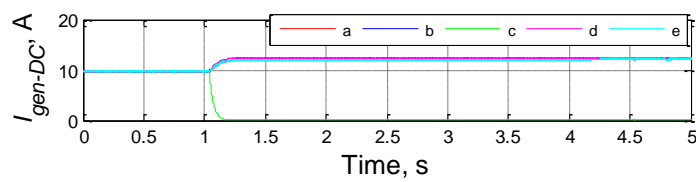

(i)

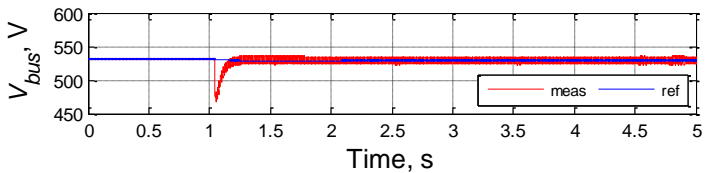

(ii)

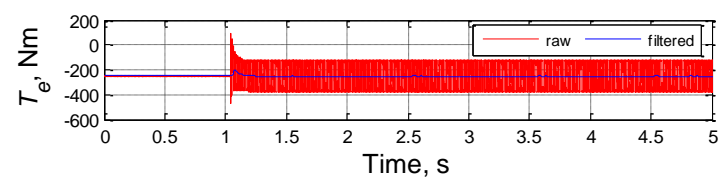

(iii)

b. experimental result [17]

d. simulation result

Figure 2. Single-phase short-circuit at $\mathrm{t}=1.03 \mathrm{~s}, 1001 \mathrm{rpm}, 540 \mathrm{~V}$, with a $26.7 \mathrm{~kW}$ resistive load 
Prior to the fault, $\mathrm{t}<1.03 \mathrm{~s}$, the five machine phases share equally the $26.7 \mathrm{~kW}$ load power as shown by the AC current in Figs. 2.a.i and 2.c.i. In both plots the per phase AC currents are $72^{\circ}$ phase displaced and approximately 50A in magnitude with a phase sequence of 'a', 'b', 'c', 'd', 'e'. Figs. 2.b.i and 2.d.i show $I_{g e n-D C}$ per phase, which are identical prior to the fault at 9.4A.

Phase ' $c$ ' is switched to a short-circuit fault at $\mathrm{t}=1.03 \mathrm{~s}$. Figs. 2.a.ii and 2.c.ii show $I_{g e n-A C}$ in the faulted phase, phase 'c', rising to the 1p.u. value (116A) due to the high winding inductance. The peak transient current from (1) is -208 A settling to 1p.u. after approximately $160 \mathrm{~ms}$, which is consistent with $I_{g e n-A C}$ peak in Figs. 2.a.ii and 2.c.ii. $I_{g e n-A C}$ in the remaining four phases, Figs. 2.a.iii and 2.c.iii, show a slight increase to approximately $60 \mathrm{~A}$ as the controller now regulates these phases to share the total power. $I_{g e n-D C}$ in the faulted phase, phase 'c', falls to zero in Figs. 2.b.i and 2.d.i and the outputs of the remaining four phases increase to $11.5 \mathrm{~A}$ to maintain the load requirements; this is possible as prior to the fault the phases were operating below the $14 \mathrm{~kW}$ maximum.

A negative deviation in the DC-bus voltage, $V_{b u s}$, is apparent when the short-circuit is applied, shown in Figs. 2.b.ii and 2.d.ii. $V_{b u s}$ falls to $467 \mathrm{~V}$ in the simulation and $468 \mathrm{~V}$ in the test results. This $73 \mathrm{~V}$ deviation in bus voltage marginally exceeds the $+60 /-70 \mathrm{~V}$ limit in MIL-STD-704F for a $270 \mathrm{~V}$ bus. A significant ripple component is apparent on $V_{b u s}$ in the test results, Fig. 2.b.ii, which was attributed to parasitic effects in the system and measurement noise. The 5V amplitude second-harmonic $V_{\text {bus }}$ ripple during faulted operation, Fig. 2.d.ii, is within the $6 \mathrm{~V}$ amplitude allowed in MIL-STD-704F. The reference value for the bus voltage is determined by the droop control and in Figs. 2.b.ii and 2.d.ii is $531.6 \mathrm{~V}$ at $\mathrm{t}<1.03 \mathrm{~s}$ and $529.6 \mathrm{~V}$ when the system is in a steady-state post fault.

A slight deviation is noticeable in the generator torque, $T_{e}$, Figs. 2.b.iii and 2.d.iii after fault occurrence. The simulation results, raw data in Fig. 2.d.iii (dark grey trace), show a secondharmonic ripple $(466 \mathrm{~Hz})$ in $T_{e}$, which is due to the unbalanced conditions when only four phases 
are active, however, due to the limited bandwidth of the mechanical couplings and the torque transducer, this is not evident in the experimental results, Fig. 2.b.iii. For comparison the simulated $T_{e}$ data is filtered, black trace in Fig. 2.d.iii and correlates closely with the measured $T_{e}$ in Fig. 2.b.iii.

The recovery of a single faulted phase at $\mathrm{t}=1 \mathrm{~s}$ is shown in Figs. 3.a. and 3.b. for the test-rig and Figs. 3.c. and 3.d. for the averaged-value simulation. Figs. 3.a.i and 3.c.i show the fault on phase 'c' approximately 1p.u. magnitude with the remaining phases generating the $26.7 \mathrm{~kW}$ load power at $1001 \mathrm{rpm}$ and approximately 66A. Phase recovery is initiated by restarting the PWM for phase 'c' at $\mathrm{t}=1 \mathrm{~s}$, shown in Figs. 3.a.ii and 3.c.ii Initially, within 500ms, the controller reduces the phase 'c' current from the fault level, then, gradually, over a period of three to four seconds the active power drawn from the phase is increased. There is a corresponding increase in the DC output current from phase ' $c$ ' and a complementary reduction in the output currents from the other phases as they adjust to share the total load current equally, Figs. 3.b.i and 3.d.i. When the recovery of phase 'c' is initiated there is only a very slight disturbance in $V_{b u s}$ and $T_{e}$, Figs. 3.b.ii, 3.b.iii, 3.d.ii and 3.d.iii, as the fault current is brought under control. Also the second-harmonic component in $T_{e}$, which is particularly evident in the simulation, is virtually eliminated once phase recovery is complete. The experimental results confirm the accuracy of the simulation model. 


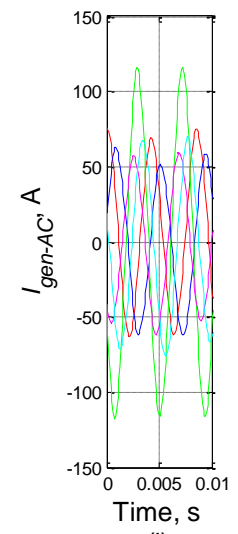

(i)

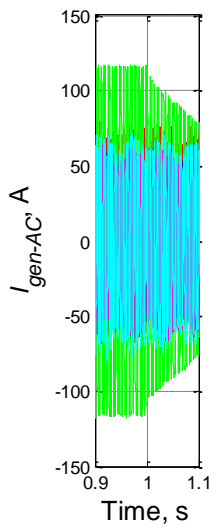

(ii)

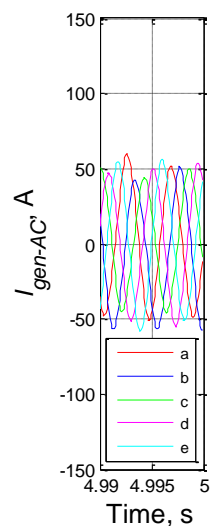

(iii)

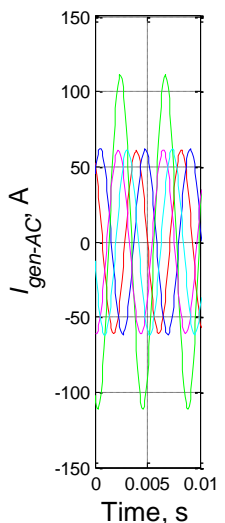

(i)

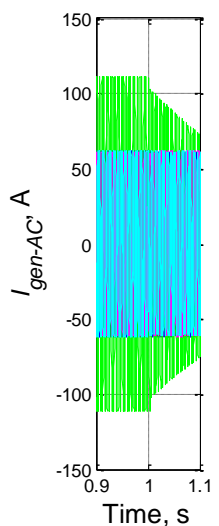

(ii)

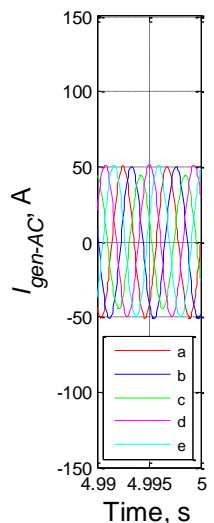

(iii)

a. experimental result [17]

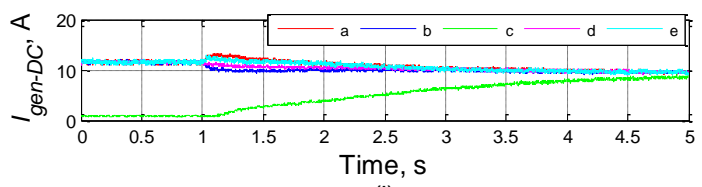

(i)

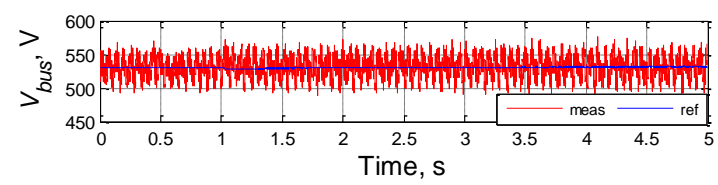

(ii)

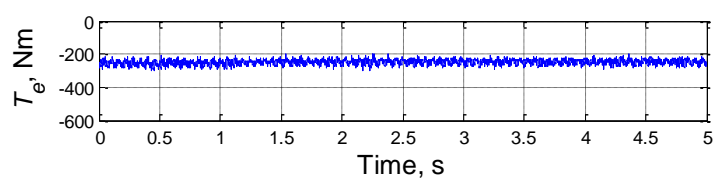

(iii)

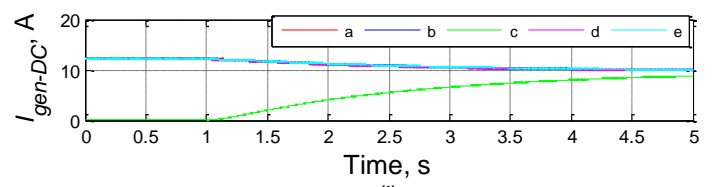

(i)

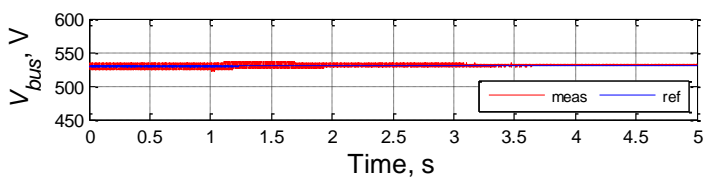

(ii)

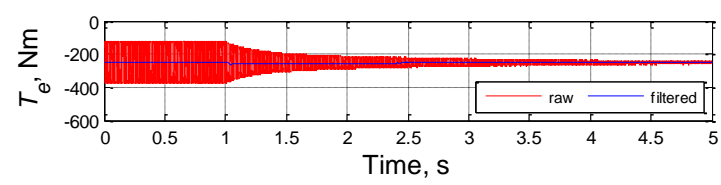

(iii)

b. experimental result [17]

d. simulation result

Figure 3. Single-phase fault recovery at $\mathrm{t}=1 \mathrm{~s}, 1001 \mathrm{rpm}, 540 \mathrm{~V}$, with a $26.7 \mathrm{~kW}$ resistive load

\section{Control of Energy Storage Device}

A multi-functional controller for the energy storage device (ESD) is described which regulates the supercapacitor current to meet transient load changes on the DC-bus, manages the supercapacitor state of charge and mitigates DC-bus voltage transients such as those caused by generator short-circuit faults. 
Supercapacitor based energy storage is proposed for a variety of applications in published literature, often as a power buffer between the load and the main power source [9, 20-29]. The control schemes are often based on a power balance between the individual hardware elements that form the system [20-22, 25-28]. These control schemes are inappropriate for this application, for example they are based on vehicle speed [22], committed power generation [20, 26], generator speed-droop characteristic [27], estimated diesel engine output [25], or are designed to enable the main power source to have a constant output [21] or require many system level measurements [28] which if extrapolated to an aircraft system would be unmanageable and may introduce communication difficulties. DC-bus voltage control schemes [23, 24, 29] for the energy storage device are not appropriate here as the bus voltage in this work is regulated by the two generator controllers.

The ESD shown in Fig. 1 is primarily intended to protect the generator and gas engine from rapid load transients, thereby limiting the rate-of-change of torque applied by the generator on the engine [16]. However it is shown later in this section, Section 5.3, that under severe DC-bus voltage transients the ESD can enter a runaway mode, due to the action of the ESD control, and collapse the DC-bus, therefore an additional control function is introduced to mitigate the voltage transients.

\subsection{Control Structure}

The ESD, Fig. 4, comprises a 55F supercapacitor bank with a maximum voltage of $145 \mathrm{~V}$ and approximately $0.4 \mathrm{MJ}$ of usable energy capacity and a simple, unisolated, bi-directional DC/DC converter [16].

A closed-loop controller is used to regulate the supercapacitor current, $I_{s c}$, and the reference value for the current controller is determined by the combination of three signals. The first, $I_{s c-L}$, is determined by the instantaneous DC-bus power calculation $\left(V_{b u s} \times I_{\text {bus }}\right.$ - where $V_{b u s}$ and $I_{b u s}$ are the bus voltage and current), which is then divided by supercapacitor voltage, $V_{s c}$. This forces the 
ESD to respond to instantaneous load changes on the DC-bus. The supercapacitor state-ofcharge is managed by the second signal, $I_{s c-r c}$, which is determined by the error between the supercapacitor reference voltage, $V_{s c}{ }^{*}$, here $135 \mathrm{~V}$, and the actual voltage. The third component, $I_{s c-F}$, is determined by the error between the DC-bus voltage and the nominal set-point. This enables the ESD to support the bus voltage during generator faults.

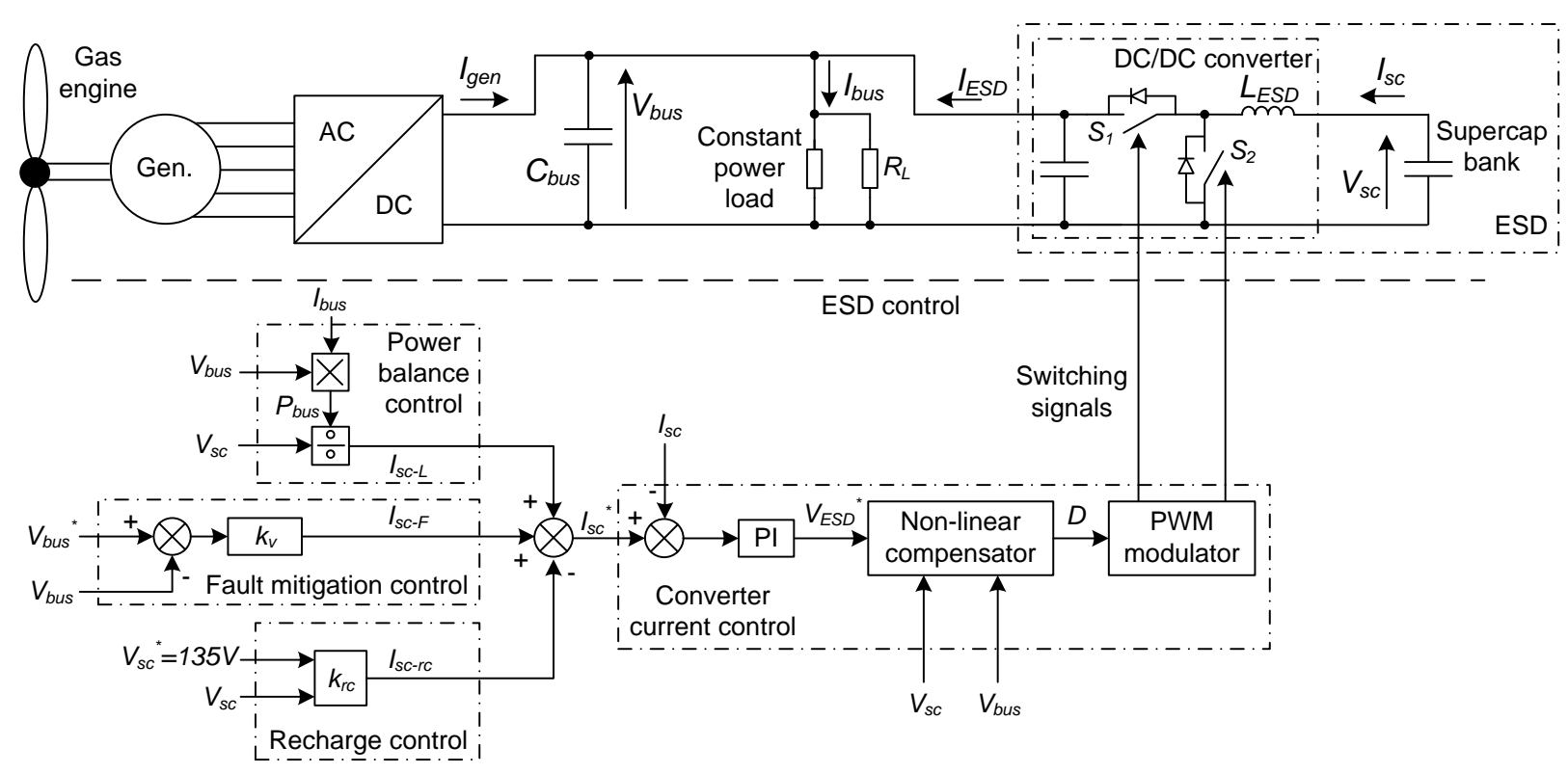

Figure 4. Overall system schematic including ESD control

\subsection{Current Control}

The current control loop was designed using the averaged-value differential equations for the DC/DC converter, which assume lossless operation and ideal switches:

$$
\begin{aligned}
& \dot{I}_{s c}=\frac{V_{s c}-V_{b u s}(1-D)}{L_{E S D}} \\
& \dot{V}_{b u s}=\frac{I_{s c}(1-D)-I_{b u s}+I_{g e n}}{C_{b u s}}
\end{aligned}
$$


where $D$ is the duty-ratio of $S 2$ and $(1-D)$ is the duty ratio of $S 1, I_{g e n}$ is the total generator DC current, $L_{E S D}$ is the DC/DC converter inductor and $C_{b u s}$ is the combined filter capacitance on the DC-bus.

A non-linear compensator is used to simplify the design of the current control loop in Fig. 4. The duty-ratio signal $D$ is calculated by the non-linear compensator as shown in (4), where $V_{E S D}{ }^{*}$ is the output signal from the PI controller, Fig. 4. By substituting (4) into the converter differential equation, (2), the overall transfer function between the control signal $V_{E S D}{ }^{*}$ and the supercapacitor current, $I_{s c}$, is seen to have a simple linear first order form, (5).

$$
\begin{gathered}
D=1-\frac{V_{s c}-V_{E S D}{ }^{*}}{V_{b u s}} \\
\frac{I_{s c}}{V_{E S D}{ }^{*}}=\frac{1}{s L_{E S D}}
\end{gathered}
$$

Assuming that the PI controller has the form $P I(s)=k_{c}\left(\left(1+T_{c} s\right) / T_{c} s\right)$, where $k_{c}$ and $T_{c}$ are the proportional and integral terms respectively, then a unity gain cross-over frequency of $\omega_{c}$ may be obtained for the control loop by choosing $k_{c}=\omega_{c} L_{E S D}$ and $T_{c}=\sqrt{10} / \omega_{c}$.

The ESD was assumed to have a switching frequency of $30 \mathrm{kHz}$, the filter inductor was $100 \mu \mathrm{H}$ and the current controller bandwidth was set at $8 \mathrm{kHz}$ by choosing $k_{c}=5.03$ and $T_{c}=62.9 \mu \mathrm{s}$. The resultant phase margin was $43^{\circ}$.

\subsection{Fault Mitigation Controller}

To illustrate the need for the fault mitigation controller, Fig. 5 shows results from a Simulink simulation of the system when a short-circuit fault is simultaneously applied to three of the generator phases. The fault is applied at approximately $\mathrm{t}=5 \mathrm{~s}$ and the DC-bus has a $14.6 \mathrm{~kW}$ resistive load and a $4.75 \mathrm{~kW}$ constant power load (CPL). The parameters of the ESD controller are as given in Section 5.2. Fig. 5 shows the five generator phase currents, the DC-bus voltage 
and the three components of the DC system current; the generator output current, $I_{g e n}$, the overall load current, $I_{b u s}$, and the ESD current, $I_{E S D}$.

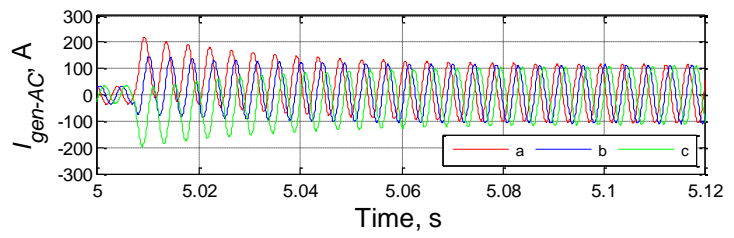

(i)

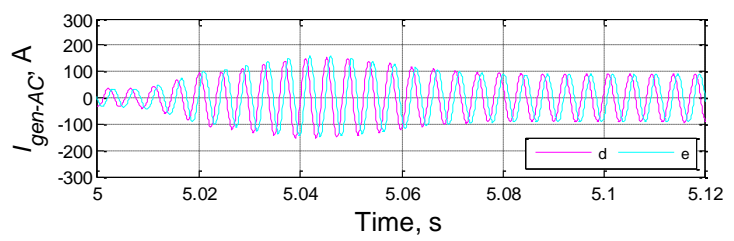

(ii)

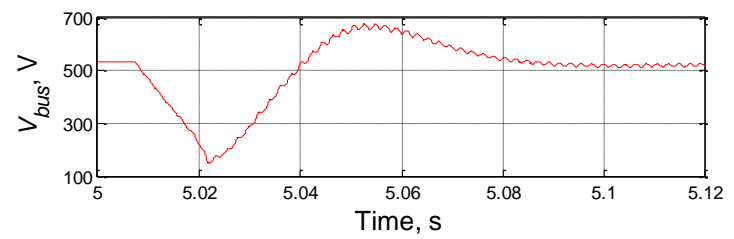

(iii)

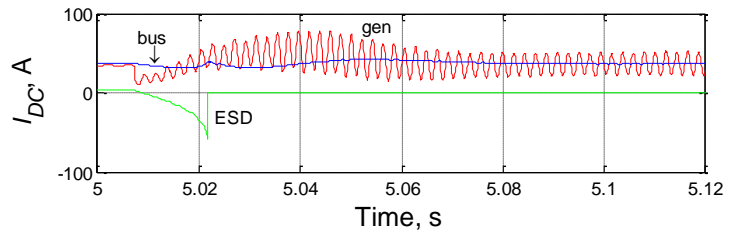

(iv)

Figure 5. System behaviour with a $14.6 \mathrm{~kW}$ resistive load and $4.75 \mathrm{~kW} \mathrm{CPL;} I_{s c-F}=0$

Pre-fault the phase currents are $35 \mathrm{~A}$, displaced by $72^{\circ}$. At approximately $\mathrm{t}=5 \mathrm{~s}$ three phases, ' $\mathrm{a}$ ', ' $b$ ' and ' $c$ ' of the five phase generator are short-circuited and after an initial transient settle to 1p.u. current. The two remaining active phases, 'd' and 'e', increase to $90 \mathrm{~A}$ to supply the load. The imposition of the fault results in a very severe DC-bus voltage transient, Fig. 5.iii, which appears to the ESD power balance controller as a sudden reduction in DC-bus power, therefore, the ESD responds with a negative $I_{E S D}$, light grey trace in Fig. 5.iv, drawing power from the DCbus which further reduces the DC-bus voltage.

Just after $t=5.02 \mathrm{~s}$ the ESD exceeds its maximum current of $60 \mathrm{~A}$ and trips out, allowing the DCbus voltage to recover through the action of the generator controller, which increases the power 
drawn from the remaining healthy phases to meet the load demand, Fig. 5.ii. Had the ESD not tripped out, the DC-bus voltage would have collapsed to the supercapacitor voltage level, forward biasing the diode in the DC/DC converter, and probably resulting in equipment failure.

To prevent the ESD from collapsing the DC-bus, the fault mitigation control function is added to the ESD system as shown in Fig. 4. A signal $I_{s c-F}$ is added to the supercapacitor current demand based on the error between the reference and actual bus voltage multiplied by a proportional gain, $k_{v}$. To ensure that the power balance control function does not degrade the DC-bus power quality during bus voltage transients $k_{v}$ must be chosen such that

$$
\left|\frac{\partial I_{s c-F}}{\partial V_{b u s}}\right| \geq\left|\frac{\partial I_{s c-L}}{\partial V_{b u s}}\right| \Rightarrow k_{v} \geq\left|\frac{I_{b u s}}{V_{s c}}\right|
$$

For the system under consideration here, the maximum value of $I_{b u s}$ is $130 \mathrm{~A}$ corresponding to $70 \mathrm{~kW}$, whilst the minimum $V_{s c}$ is assumed to be $100 \mathrm{~V}$, implying a minimum value of $k_{v}$ of 1.3 .

However, using a larger value will result in the ESD tending to mitigate transient deviations in the DC-bus voltage. The maximum value of $k_{v}$ is limited by stability concerns. From (3) the transfer function between $V_{b u s}$ and $I_{s c}{ }^{*}$ may be approximated by (7) within the current control loop bandwidth.

$$
\frac{V_{b u s}}{I_{s c}}=\frac{(1-D)}{s C_{b u s}}
$$

Therefore to limit the bandwidth of the voltage control loop to $\omega_{v}$, the proportional gain $k_{v}$ must be equal to $\omega_{v} C_{\text {bus }} /(1-D)$. For the system under consideration, choosing $k_{v}=15$ sets the bandwidth of the voltage control loop at $800 \mathrm{~Hz}$, well below the current control loop bandwidth to prevent any interactions between the loops. 


\subsection{State-of-Charge Controller}

The state-of-charge controller provides a contribution, $I_{s c-r c}$, to the overall supercapacitor current reference, $I_{s c}{ }^{*}$, based on the error between the actual supercapacitor voltage and its fully charged value, which is $135 \mathrm{~V}$ in this case. Since under steady-state conditions the supercapacitor current tends to zero, then the $I_{s c-r c}$ and $I_{s c-L}$ components of supercapacitor current must be equal, resulting in the supercapacitor voltage falling with increasing DC-bus power. This ensures that the supercapacitor is fully charged under no-load conditions and is therefore able to supply transient load increases. In contrast the supercapacitor will be heavily discharged when the DCbus is fully loaded and therefore able to absorb power in the event of transient load decreases.

A non-linear recharge function, $k_{r c}=0.64\left(V_{s c}{ }^{*}-V_{s c}\right)^{2}$, was used to regulate the supercapacitor voltage recharge. $k_{r c}$ was chosen to give a $33 \mathrm{~V}$ drop in $V_{s c}$ at $70 \mathrm{~kW}$ load power, as shown in Fig. 6, and results in the ESD output settling in approximately 10 s.

An additional droop in $V_{s c}$ with DC-bus power occurs due to the action of the fault mitigation control function, which produces a non-zero output under steady-state conditions. This is because the DC-bus voltage droops with load due to the action of the generator control unit whereas the nominal DC-bus voltage is used as the reference signal in the fault mitigation function. The effect on the steady-state supercapacitor voltage is seen in Fig. 6, which shows the voltage with and without the fault mitigation controller active.

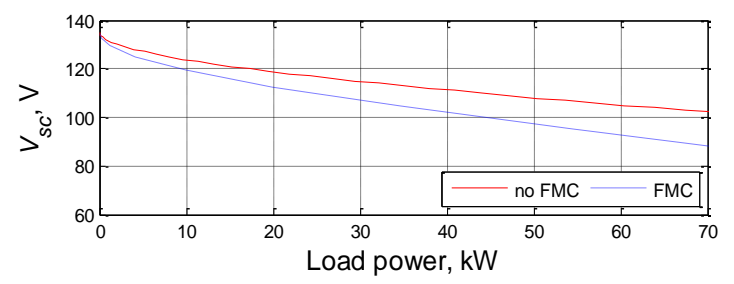

Figure 6. Supercapacitor voltage droop characteristic 


\section{Multi-Phase Fault Response with Energy Storage Device}

The DC-bus voltage and generator torque are examined in this section by means of simulation during multi-phase generator faults with combined resistive and constant power loads on the bus, both with and without the ESD. All results relate to three generator phases suffering simultaneous short-circuit faults, with all phases being faulted on the zero crossing of phase ' $a$ ' terminal voltage, which results in a higher deviation in DC-bus voltage compared to the staggered faulting of the phases.

\subsection{Combined Resistive and Constant Power Load}

The bus is nominally loaded with $14.6 \mathrm{~kW}$ of resistive load and $9.5 \mathrm{~kW}$ of constant power load (CPL) which, when combined, is approximately the maximum power output of two active phases. The speed is constant at the minimum operating speed of 1000rpm as the phase current and torque are highest. The above conditions result in one of the worst case scenarios for the generator in normal service.

Fig. 7.i shows the AC-current of the faulted phases and the Fig. 7.ii shows the AC current of the healthy phases. The phase currents are plotted separately for clarity. Fig. 7.iii shows bus voltage and Fig. 7.iv is the generator torque.

In Figs. 7 and 8 the bus is initially loaded with $14.6 \mathrm{~kW}$ of resistive load and $9.5 \mathrm{~kW}$ of CPL and all five generator phases are active. $I_{g e n-A C}$ per phase are $72^{\circ}$ phase displaced with respect to the adjacent phase and all are 46A. At $\mathrm{t}=5 \mathrm{~s}$ three generator phases, ' $\mathrm{a}$ ', ' $\mathrm{b}$ ' and 'c', suffer shortcircuit faults. $I_{g e n-A C}$ 'a', 'b' and 'c' increase to a magnitude of 1 p.u. and $I_{g e n-A C}$ 'd' and 'e' increase to $116 \mathrm{~A}$ to maintain power to the loads. At $\mathrm{t}=10 \mathrm{~s}$ the $9.5 \mathrm{~kW} \mathrm{CPL}$ is turned off for $5 \mathrm{~s}$ then on again and finally at $\mathrm{t}=25 \mathrm{~s}$ the three generator phases are restarted, $I_{g e n-A C}$ ' $\mathrm{d}$ ' and 'e' reduce to $70 \mathrm{~A}$ when the $\mathrm{CPL}$ is off then increase to $116 \mathrm{~A}$ when the $\mathrm{CPL}$ is restarted. $I_{\text {gen-AC }}$ 'a', 
' $\mathrm{b}$ ' and ' $\mathrm{c}$ ' are unaffected by the changes in CPL. When the phases are restarted $I_{g e n-A C}$ are automatically adjusted by the control to be $46 \mathrm{~A}$ so that all phases equally share the load.

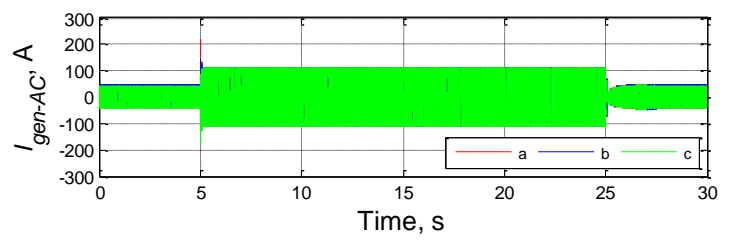

(i)

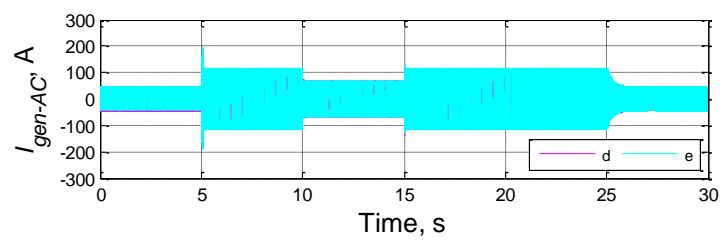

(ii)

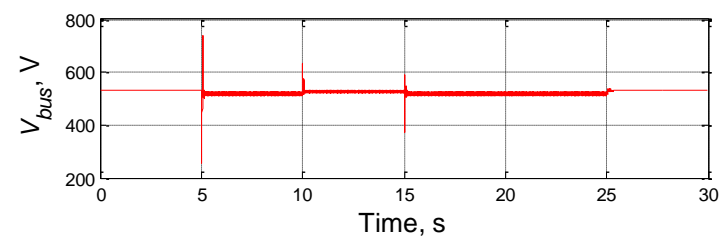

(iii)

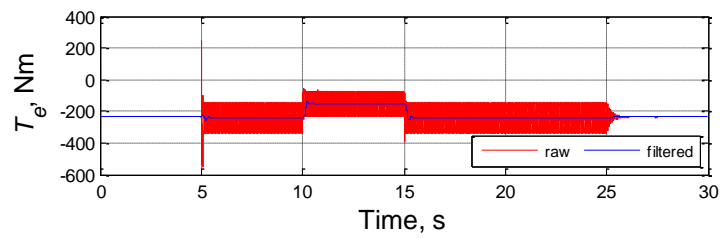

(iv)

Figure 7. System behaviour with $14.6 \mathrm{~kW}$ resistive and 9.5kW CPL; ESD inactive

In Fig. 7, with the ESD inactive, fault occurrence at $\mathrm{t}=5 \mathrm{~s}$ results in $V_{\text {bus }}$ deviations of $+206 /-$ $282 \mathrm{~V}$, exceeding the MIL-STD-704F limits of $+60 /-70 \mathrm{~V}$ for a $270 \mathrm{~V}$ system. Switching the $9.5 \mathrm{~kW}$ CPL off at $\mathrm{t}=10 \mathrm{~s}$ and back on at $\mathrm{t}=15 \mathrm{~s}$, also results in large bus transients. Due to the controller design, the phase recovery at $\mathrm{t}=25 \mathrm{~s}$ results in a gradual adjustment of the generator currents and virtually no deviation in $V_{\text {bus }}$, Fig. 7.iii. Fault and bus load changes at $\mathrm{t}=5,10$ and $15 \mathrm{~s}$, result in large transients in AC-current, $I_{g e n-A C}$, and torque, $T_{e}$, in Figs. 7.i, 7.ii and 7.iv.

During the faulted generator condition when only two phases are active, $5<\mathrm{t}<25 \mathrm{~s}$, the secondharmonic component is noticeable on $V_{\text {bus }}$ and $T_{e}$, Figs. 7.iii and 7.iv; outside this time range the second-harmonics of the five active phases cancel. A $96 \mathrm{Nm}$ second-harmonic ripple is apparent 
on $T_{e}$ during the high-load conditions $5<\mathrm{t}<10 \mathrm{~s}$ and $15<\mathrm{t}<25 \mathrm{~s}$ which would be attenuated by the mechanical system in practice. The $8.5 \mathrm{~V}$ amplitude second-harmonic ripple on $V_{b u s}$ during highload exceeds the MIL-STD-704F limit of 6V.

Fig. 8 shows the system behaviour for the same events as in Fig. 7 but with the ESD active. Fig. 8.i shows $I_{g e n-A C}$ of the faulted phases and Fig.8.ii shows $I_{g e n-A C}$ of the healthy phases. The deviations in $V_{\text {bus }}$, Fig. 8.iii, are almost eliminated at the instants of fault occurrence and load switching; the minimum and maximum values of $V_{b u s}$ being $514 \mathrm{~V}$ and $530 \mathrm{~V}$, well within the MIL-STD-704F limits. $I_{g e n-A C}$ and $T_{e}$ (Figs. 8.i, 8.ii and 8.iv) exhibit very mild variations except at fault occurrence due to the ESD which rapidly responds to $V_{b u s}$ deviations in the case of faults or phase recovery by supplying / drawing power to / from the bus. The high current and torque peaks immediately after fault occurrence are unchanged in Figs. 7 and 8 as the ESD has no direct effect on generator currents.

The second-harmonic torque ripple is unchanged in Fig. 8 since there is no change in the generator currents. However, the DC-bus voltage ripple is reduced from $8.5 \mathrm{~V}$, in Fig. 7 , to $6.3 \mathrm{~V}$ in Fig. 8 by the action of the fault mitigation function, which produces a component of ESD current that is in anti-phase with the generator second-harmonic current. The cancellation of second-harmonic current is far from complete due to the relatively low bandwidth $(800 \mathrm{~Hz})$ of the fault mitigation loop in the ESD. Furthermore this effect will be less pronounced at higher generator speeds. Fig. 8.v shows the contributions of the generator and ESD to bus current, the second-harmonic component in $I_{E S D}$ is clearly visible during faulted operation. Negative ESD current, and an increase in $V_{s c}$, Fig. 8.vi, indicates power drawn from the bus. The ESD output settles to zero in approximately 10 s. 


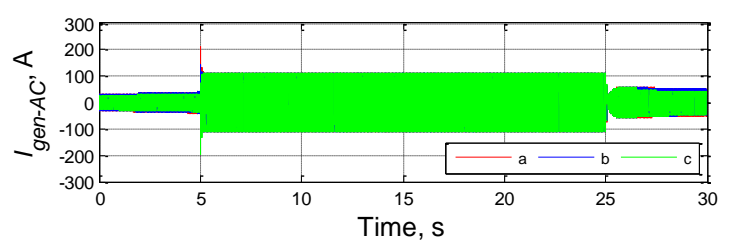

(i)

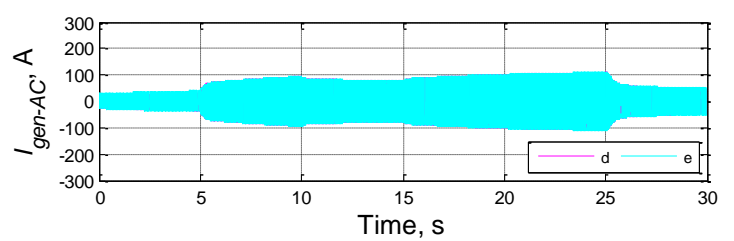

(ii)

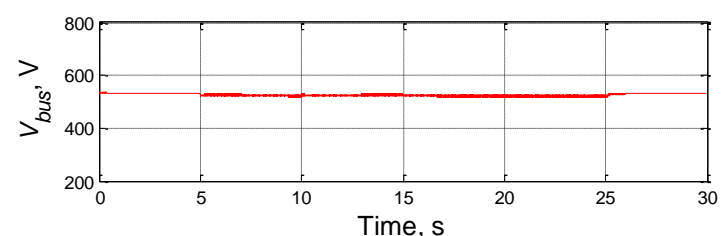

(iii)

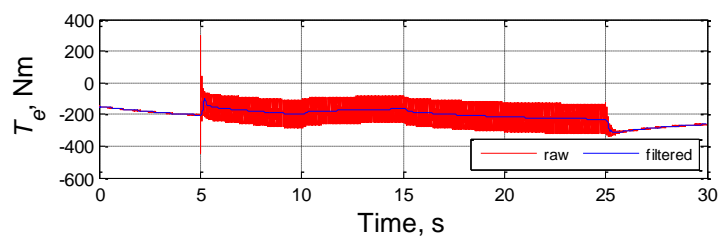

(iv)

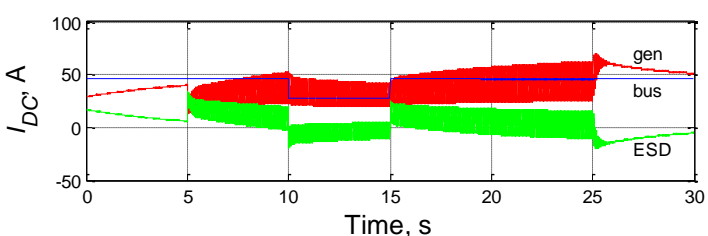

(v)

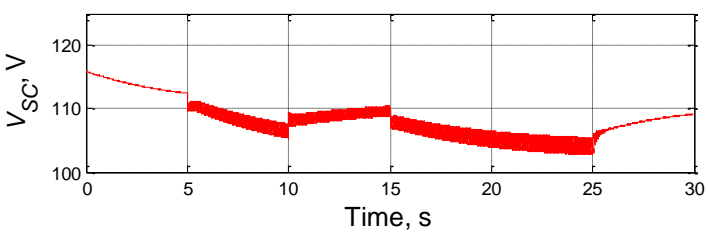

(vi)

Figure 8. System behaviour with $14.6 \mathrm{~kW}$ resistive and 9.5kW CPL; ESD active

\subsection{Entirely Constant Power Load}

Fig. 9 shows the system behaviour when a $24 \mathrm{~kW}$ constant power load is present on the DC-bus with the generator and ESD active during bus voltage switching, load switching and generator fault events. In Fig. 9 the bus voltage reference value is initially $540 \mathrm{~V}$ and at $\mathrm{t}=2 \mathrm{~s}$ the voltage 
reference is increased to $560 \mathrm{~V}$ with a $10 \mathrm{~ms}$ rise-time, at $\mathrm{t}=5 \mathrm{~s}$ three generator phases, ' $\mathrm{a}$ ', ' $\mathrm{b}$ ' and 'c', suffer short-circuit faults and are restarted 9s later, between $9<\mathrm{t}<11 \mathrm{~s}$ the CPL is halved to $12 \mathrm{~kW}$ and finally at $\mathrm{t}=17 \mathrm{~s}$ the voltage reference is restored to $540 \mathrm{~V}$ over $10 \mathrm{~ms}$.

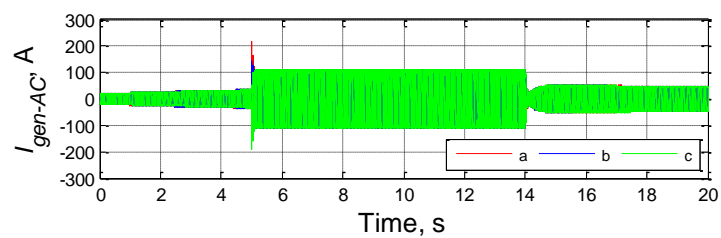

(i)

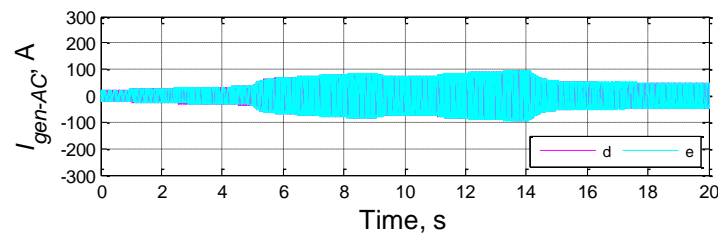

(ii)

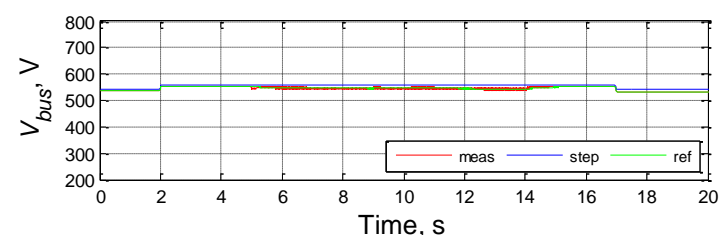

(iii)

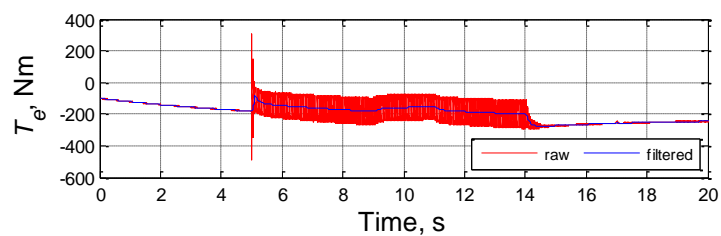

(iv)

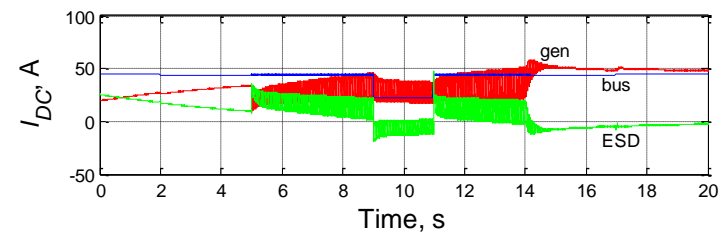

(v)

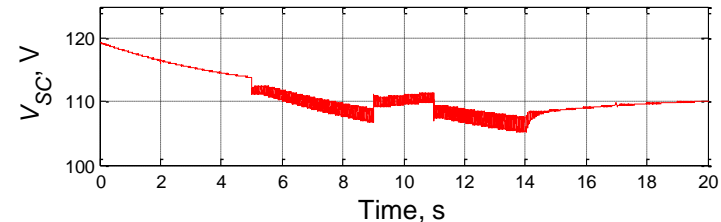

(vi)

Figure 9. System behaviour with $24 \mathrm{~kW}$ constant power load (CPL) during $V_{b u s}{ }^{*}$ switching events; ESD active

In Fig. 9 steps in bus voltage reference, $V_{\text {bus }}{ }^{*}$, at $\mathrm{t}=2 \mathrm{~s}$ and $\mathrm{t}=17 \mathrm{~s}$ result in a controlled response in $V_{\text {bus }}$, Fig. 9.iii, due to the combined action of the generator control and ESD. The ESD shows 
a small deviation in output (3A), Fig. 9.v, due to the $V_{b u s}{ }^{*}$ step change. As in Fig. 8 the ESD minimises deviations in $V_{\text {bus }}$ during fault occurrence, $\mathrm{t}=5 \mathrm{~s}$ in Fig. 9, and during load changes at $\mathrm{t}=9 \mathrm{~s}$ and $\mathrm{t}=11 \mathrm{~s} . \quad I_{\text {gen }-A C}$ and $T_{e}$, the Figs. 9.i, 9.ii and 9.iv contain a transient following the generator fault condition as the ESD has no direct effect on generator currents. Figs. 9.v and 9.vi confirm the performance of the ESD during both generator fault occurrence and load changes.

Interestingly, with only constant power loads in the system, the DC-bus becomes unstable when the ESD is disconnected, illustrating a further benefit of the device.

\section{Conclusions}

Experimental results on a five-phase, fault-tolerant generator show that a single-phase AC short-circuit fault results in excessive DC-bus voltage deviations. A simulation model based on the test results is then used to show that an energy storage device with a load-tracking, power balance controller enters a runaway mode during such transients. To overcome this problem a simple fault mitigation function is added to the energy storage device to control the DC-bus transient during short-circuit faulted operation of the generator. The fault mitigation controller enables the energy storage device to respond instantaneously to generator faults, virtually eliminating voltage transients from the DC-bus. The simulation model was then extended to impose a three phase short-circuit fault on the five phase generator, which represents one of the worst case fault scenarios. Combined resistive and constant power loads, were used to demonstrate the system performance under faulted generator conditions both with and without the energy storage device. The energy storage device was also seen to provide some attenuation of the second-harmonic bus voltage ripple that occurs during generator fault conditions. A bus switching event represented by a step in DC-bus reference voltage was also examined to demonstrate the robustness of the energy storage device control. 
The energy storage device, with a multi-input controller, has been demonstrated to be multifunctional in that it mitigates DC-bus voltage transients which occur as a result of normal events on the DC-bus, such as generator short-circuit faults, load changes (combined resistive and constant power) and bus switching events represented by step changes in voltage reference. Combining functionality in a single electrical subsystem, as in the case of this energy storage device, minimises the increase in system weight which is a critical factor in aircraft applications. The significant reduction in voltage deviations during normal events on the DC-bus when the energy storage device is online enables the limits in MIL-STD-704F to be respected.

More generally the work in this paper illustrates the importance of energy storage in on-board power networks for a range of functions including power quality management, system stability and the control of transients on the prime mover. Optimising these multiple objectives and the capacity of the energy storage device are topics for further research.

\section{Acknowledgements}

The authors would like to thank Rolls-Royce plc for funding this work, which forms part of the Intelligent Electrical Power Network Evaluation Facility (IEPNEF) which is housed in the Rolls-Royce University Technology Centre (UTC) for Electrical Systems in Extreme Environments at The University of Manchester. IEPNEF has been developed to evaluate ultracompact and intelligent electrical networks for aerospace, marine and energy applications.

\section{References}

[1] A. M. El-Refaie, "Fault-Tolerant Permanent Magnet Machines: A Review," IET Electric Power Applications, vol. 5, pp. 59-74, 2011.

[2] J. A. Haylock, B. C. Mecrow, A. G. Jack, and D. J. Atkinson, "Operation of a Fault Tolerant PM Drive for an Aerospace Fuel Pump Application," IEE Proceedings - Electric Power Applications, vol. 145, pp. 441448, 1998.

[3] B. C. Mecrow, A. G. Jack, J. A. Haylock, and J. Coles, "Fault-Tolerant Permanent Magnet Machine Drives," IEE Proceedings - Electric Power Applications, vol. 143, pp. 437-442, 1996.

[4] L. Parsa and H. A. Toliyat, "Fault-Tolerant Five-Phase Permanent Magnet Motor Drives," presented at the Conference Record of the IEEE Industry Applications Conference 39th IAS Annual Meeting, 2004.

[5] K. Emadi and M. Ehsani, "Aircraft Power Systems: Technology, State of the Art, and Future Trends," IEEE Aerospace and Electronic Systems Magazine, vol. 15, pp. 28-32, 2000. 
[6] D. Izquierdo, R. Azcona, F. del Cerro, C. Fernandez, and B. Delicado, "Electrical Power Distribution System (HV270DC), for Application in More Electric Aircraft," presented at the Twenty-Fifth Annual IEEE Applied Power Electronics Conference and Exposition (APEC), 2010.

[7] A. Lucken, J. Brombach, and D. Schulz, "Design and protection of a high voltage DC onboard grid with integrated fuel cell system on more electric aircraft," in Electrical Systems for Aircraft, Railway and Ship Propulsion (ESARS), 2010, pp. 1-6.

[8] A. Martin, "A Review of Active Rectification in Aircraft AC Systems," in More Electric Aircraft Forum, http://www.eurtd.com/moet/PDF/K.pdf accessed on 5/7/11, 2009.

[9] H. Zhang, F. Mollet, C. Saudemont, and B. Robyns, "Experimental Validation of Energy Storage System Management Strategies for a Local DC Distribution System of More Electric Aircraft," IEEE Transactions on Industrial Electronics, vol. 57, pp. 3905-3916, 2010.

[10] Department of Defense (United States of America) Interface Standard Aircraft Electric Power Characteristics, "MIL-STD-704F," March 2004.

[11] A. J. Mitcham and J. J. A. Cullen, "Permanent Magnet Generator Options for the More Electric Aircraft," presented at the International Conference on Power Electronics, Machines and Drives (PEMD), 2002.

[12] M. J. Provost, "The More Electric Aero-engine: A General Overview from an Engine Manufacturer," presented at the International Conference on (Conf. Publ. No. 487) Power Electronics, Machines and Drives (PEMD), 2002.

[13] R. Cuzner, D. MacFarlin, D. Clinger, M. Rumney, and G. Castles, "Circuit Breaker Protection Considerations in Power Converter-Fed DC Systems," in IEEE Electric Ship Technologies Symposium (ESTS), 2009, pp. 360-367.

[14] X. Liu, Y. Zhou, and S. Ma, "EMI filter design for constant power loads in more electric aircraft power systems," presented at the IEEE 6th International Power Electronics and Motion Control Conference, (IPEMC), May 2009.

[15] A. Khaligh and L. Zhihao, "Battery, Ultracapacitor, Fuel Cell, and Hybrid Energy Storage Systems for Electric, Hybrid Electric, Fuel Cell, and Plug-In Hybrid Electric Vehicles: State of the Art," IEEE Transactions on Vehicular Technology, vol. 59, pp. 2806-2814, 2010.

[16] R. Todd, D. Wu, J. A. dos Santos Girio, M. Poucand, and A. J. Forsyth, "Supercapacitor-Based Energy Management for Future Aircraft Systems," presented at the Twenty-Fifth Annual IEEE Applied Power Electronics Conference and Exposition (APEC), Palm Springs, CA., 2010.

[17] R. Todd and A. J. Forsyth, "Control of Multi-Phase Fault-Tolerant PM Generator," presented at the UK Magnetics Society More Electric Aircraft One-Day Seminar, Bristol, April 2009.

[18] R. Todd and A. J. Forsyth, "HIL Emulation of All-Electric UAV Power Systems," presented at the IEEE Energy Conversion Congress and Exposition (ECCE), San Jose, CA., 2009.

[19] Z. Sun, J. Wang, D. Howe, and G. Jewell, "Analytical Prediction of the Short-Circuit Current in FaultTolerant Permanent-Magnet Machines," IEEE Transactions on Industrial Electronics, vol. 55, pp. 42104217, 2008.

[20] C. Abbey and G. Joos, "Supercapacitor Energy Storage for Wind Energy Applications," IEEE Transactions on Industry Applications, vol. 43, pp. 769-776, 2007.

[21] F. Baalbergen, P. Bauer, and J. A. Ferreira, "Energy Storage and Power Management for Typical 4Q-Load," IEEE Transactions on Industrial Electronics, vol. 56, pp. 1485-1498, 2009.

[22] J. Dixon, I. Nakashima, E. F. Arcos, and M. Ortuzar, "Electric Vehicle Using a Combination of Ultracapacitors and ZEBRA Battery," IEEE Transactions on Industrial Electronics, vol. 57, pp. 943-949, 2010.

[23] A. A. Ferreira, J. A. Pomilio, G. Spiazzi, and L. de Araujo Silva, "Energy Management Fuzzy Logic Supervisory for Electric Vehicle Power Supplies System," IEEE Transactions on Power Electronics, vol. 23, pp. 107-115, 2008.

[24] Y. Hyunjae, S. Seung-Ki, P. Yongho, and J. Jongchan, "System Integration and Power-Flow Management for a Series Hybrid Electric Vehicle Using Supercapacitors and Batteries," IEEE Transactions on Industry Applications, vol. 44, pp. 108-114, 2008.

[25] L. Joon-Hwan, L. Seung-Hwan, and S. Seung-Ki, "Variable-Speed Engine Generator With Supercapacitor: Isolated Power Generation System and Fuel Efficiency," IEEE Transactions on Industry Applications, vol. 45, pp. 2130-2135, 2009.

[26] Q. Liyan and Q. Wei, "Constant Power Control of DFIG Wind Turbines With Supercapacitor Energy Storage," IEEE Transactions on Industry Applications, vol. 47, pp. 359-367, 2011.

[27] K. Sang-Min and S. Seung-Ki, "Control of Rubber Tyred Gantry Crane With Energy Storage Based on Supercapacitor Bank," IEEE Transactions on Power Electronics, vol. 21, pp. 1420-1427, 2006.

[28] K. Tae-Suk, L. Seon-Woo, S. Seung-Ki, P. Cheol-Gyu, K. Nag-In, K. Byung-il, and H. Min-seok, "Power Control Algorithm for Hybrid Excavator With Supercapacitor," IEEE Transactions on Industry Applications, vol. 46, pp. 1447-1455, 2010. 
[29] P. Thounthong, P. Sethakul, S. Rael, and B. Davat, "Performance Investigation of Fuel Cell/Battery and Fuel Cell/Supercapacitor Hybrid Sources for Electric Vehicle Applications," presented at the 4th IET Conference on Power Electronics, Machines and Drives (PEMD), 2008. 